\title{
Discussion
}

\section{"And yet it moves" or why grammar overrides frequency: a reply to Kempen and Harbusch}

\author{
Ina Bornkessel ${ }^{\mathrm{a}, *}$, Matthias Schlesewsky ${ }^{\mathrm{b}}$, Angela D. Friederici ${ }^{\mathrm{a}}$ \\ ${ }^{a}$ Max Planck Institute of Cognitive Neuroscience, Leipzig, Germany \\ bunior Research Group Neurolinguistics, Philipps University Marburg, Marburg, Germany
}

Received 27 June 2003; accepted 4 July 2003

\begin{abstract}
We show that Kempen and Harbusch's (Cognition (2003) this issue) arguments against our claims cannot be upheld. On the one hand, their alternative account of our data that is based on the availability of constructions with object-experiencer verbs is not compatible with the literature on the processing of these types of sentences in German. Moreover, their allegation that we failed to conduct an accurate corpus count is simply a misreading of our paper. Insofar, the commentary in no way casts doubt on our claim that grammatical regularities override frequency during online comprehension.
\end{abstract}

(C) 2003 Elsevier B.V. All rights reserved.

Keywords: Grammar; Frequency; Kempen and Harbusch; Sentence processing; Event-related brain potentials; Word order; Case marking

In their comment on our paper, Kempen and Harbusch (2003) (henceforth K\&H) argue that we "have overlooked an important class of dative constructions in German and misinterpreted the corpus frequency data". As we will show below, both of these claims are mistaken.

$\mathrm{K} \& \mathrm{H}$ argue that initial datives are not only unmarked as the sole argument of a passive clause, but also as part of a dative-nominative word order with object-experiencer verbs such as gefallen ('to be pleasing to'). They suggest that this observation, which was not discussed in our paper, leads to a fundamentally different perspective on our ERP data. In fact, we have discussed dative object-experiencer verbs and the word order patterns

\footnotetext{
* Corresponding author. Max Planck Institute of Cognitive Neuroscience, P.O. Box 5003 55, 04303 Leipzig, Germany. Tel.: +49-341-9940-114; fax: +49-341-9940-113.

E-mail address: bornke@cns.mpg.de (I. Bornkessel).
} 
associated with them extensively in a number of recent publications (Bornkessel, 2002; Bornkessel, Schlesewsky, \& Friederici, 2002, 2003; Schlesewsky \& Bornkessel, 2003, in press). While $\mathrm{K} \& \mathrm{H}$ are correct in assuming that these verbs are associated with a preference for a dative-initial order in off-line acceptability ratings (Schlesewsky \& Bornkessel, 2003), the on-line applicability of this preference cannot be straightforwardly assumed. As shown in Bornkessel (2002) and Schlesewsky and Bornkessel (in press), a dative object-experiencer verb such as gefällt ('to be pleasing to') does not induce a preference for dative-initiality even in sentences such as (1), where the specific properties of the verb are available before the arguments are processed. Rather, enhanced processing costs were always observable for dative-initial structures, either at the unambiguously marked dative NP (1a) or in the form of reanalysis at the position of the second argument when the first NP is ambiguous with respect to case (1b).

(1) a. Vielleicht folgt/gefällt dem Jäger der Gärtner. perhaps follows/pleases [the hunter] $]_{\text {DAT }}[\text { the gardener }]_{\text {NOM }}$ 'Perhaps the gardener follows/is pleasing to the hunter.'

b. Vielleicht folgt/gefällt Richard der Gärtner. perhaps follows/pleases Richard ${ }_{\text {NOM/ACC/DAT }}[\text { the gardener }]_{\text {NOM }}$ 'Perhaps the gardener follows/is pleasing to Richard.'

Thus, seeing that the off-line advantage for a dative-nominative order for the gefallenclass does not guide on-line processing, the passive-based explanation of our data is the logical consequence.

Moreover, the data from the verb-second constructions in (1) also show that K\&H's alternative interpretation of the positivity at the position of NP2 in our study is not correct. Under their account, which assumes that the positivity reflects the falsification of the expectation for an "inanimate or even abstract subject NP", the same expectation should have applied in sentences like (1). This, however, was not the case (Bornkessel, 2002; Schlesewsky \& Bornkessel, in press).

$\mathrm{K} \& \mathrm{H}$ 's second major point concerns our interpretation of our corpus data, which they question on two grounds, namely (a) that the determiner den is ambiguous between accusative singular and dative plural, and (b) that the word order pattern dativenominative is more frequent than accusative-nominative.

Firstly, as stated in our paper, we analyzed occurrences of dass ('that') + den ('the ACCUSATIVE' ). As suggested by this formulation, only accusative occurrences of den were taken into account. This was ensured by a manual examination of all ambiguous cases within the 10000 randomly sampled sentences underlying our corpus analysis. This "manual disambiguation" was also justified in view of the presentation mode employed in our ERP study, in which NPs were presented as a whole in order to ensure that there would be no ambiguity of case marking. Previous findings support the assumption that determiners and nouns are indeed processed together under these circumstances (e.g. Frisch \& Schlesewsky, 2001). Our corpus count therefore did not overestimate the frequency of accusative-initial structures.

Secondly, K\&H's presentation of their frequency data indicates that their perspective is not based on the (local) transition probability from a complementizer to the first argument, 
but rather on a global notion of argument order frequency. However, taking the complete constituent structure of the clause (rather than a left-corner style prediction of the next constituent) into account is a quasi off-line perspective. Indeed, we explicitly stated in our paper that "factors such as frequency may indeed play a role with regard to global properties of sentence comprehension" (p. B29). Possible correlations between corpus data and acceptability judgements (e.g. Keller, 2000; Pechmann, Uszkoreit, Engelkamp, \& Zerbst, 1994) or other off-line measures fall out naturally from this perspective.

Finally, it is somewhat surprising that the NEGRA-based frequency ratios reported by $\mathrm{K} \& \mathrm{H}$ with regard to accusative- vs. dative-initial structures differ from publication to publication. While in the commentary on our paper, it is argued that "it is much more likely for a full dative than for a full accusative to precede the subject", in another recent article Kempen and Harbusch (in press) note that “in contrast with Bornkessel et al.'s results, permutations starting with direct objects tend to be more frequent than those with initial indirect objects" (Footnote 3). This incertitude renders their argumentation highly questionable at the very least.

To conclude, none of K\&H's arguments are capable of weakening the claims of our paper. Clause medial word order variations in German therefore remain a challenge for frequency-based accounts of online language comprehension.

\section{References}

Bornkessel, I. (2002). The argument dependency model: a neurocognitive approach to incremental interpretation MPI-Series in cognitive neuroscience, 28. Leipzig: MPI.

Bornkessel, I., Schlesewsky, M., \& Friederici, A. D. (2002). Beyond syntax: language-related positivities reflect the revision of hierarchies. NeuroReport, 13, 361-364.

Bornkessel, I., Schlesewsky, M., \& Friederici, A. D. (2003). Eliciting thematic reanalysis effects: the role of syntax-independent information during parsing. Language and Cognitive Processes, 18, 268-298.

Frisch, S., \& Schlesewsky, M. (2001). The N400 indicates problems of thematic hierarchizing. NeuroReport, 12, 3391-3394.

Keller, F (2000). Gradience in grammar: experimental and computational aspects of degrees of grammaticality. Doctoral dissertation, University of Edinburgh.

Kempen, G., \& Harbusch, K (2003). An artificial opposition between grammaticality and frequency: comment on Bornkessel, Schlesewsky, and Friederici (2002). Cognition, this issue.

Kempen, G., \& Harbusch, K (in press). Word order scrambling as a consequence of incremental sentence production. In H. Härtl, \& H. Tappe (Eds.), Mediating between concepts and grammar (= Trends in Linguistics). Berlin/New York: Mouton de Gruyter.

Pechmann, T., Uszkoreit, H., Engelkamp, J., \& Zerbst, D (1994). Word order in the German middle field: linguistic theory and psycholinguistic evidence (Report No. 43). Saarbrücken: Department of Computational Linguistics at the University of the Saarland.

Schlesewsky, M., \& Bornkessel, I. (2003). Ungrammaticality detection and garden path strength: a commentary on Meng and Bader's (2000) evidence for serial parsing. Language and Cognitive Processes, 18, 299-311.

Schlesewsky, M., \& Bornkessel, I (in press). On incremental interpretation: degrees of meaning accessed during language comprehension. Lingua, special issue on Variation in Form versus Variation in Meaning. 